\title{
Determinants of adverse birth outcome in Sub-Saharan Africa: analysis of recent demographic and health surveys
}

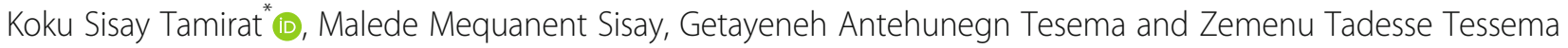

\begin{abstract}
Background: More than $75 \%$ of neonatal deaths occurred in the first weeks of life as a result of adverse birth outcomes. Low birth weight, preterm births are associated with a variety of acute and long-term complications. In Sub-Saharan Africa, there is insufficient evidence of adverse birth outcomes. Hence, this study aimed to determine the pooled prevalence and determinants of adverse birth outcomes in Sub-Saharan Africa.

Method: Data of this study were obtained from a cross-sectional survey of the most recent Demographic and Health Surveys (DHS) of ten Sub-African (SSA) countries. A total of 76,853 children born five years preceding the survey were included in the final analysis. A Generalized Linear Mixed Models (GLMM) were fitted and an adjusted odds ratio (AOR) with a 95\% Confidence Interval (Cl) was computed to declare statistically significant determinants of adverse birth outcomes.

Result: The pooled prevalence of adverse birth outcomes were $29.7 \%$ (95\% Cl: 29.4 to 30.03). Female child (AOR= 0.94, 95\%Cl: 0.91 0.97), women attended secondary level of education ( $\mathrm{AOR}=0.87,95 \% \mathrm{Cl}: 0.82$ 0.92), middle ( $\mathrm{AOR}=$ 0.94,95\%Cl: 0.90 0.98) and rich socioeconomic status (AOR $=0.94,95 \% \mathrm{Cl}: 0.90$ 0.99), intimate-partner physical violence (beating) $(A O R=1.18,95 \% \mathrm{Cl}: 1.141 .22)$, big problems of long-distance travel (AOR=1.08, 95\%Cl: 1.041 .11$)$, antenatal care follow-ups ( $A O R=0.86,95 \% \mathrm{Cl}: 0.83$ 0.86), multiparty ( $\mathrm{AOR}=0.88,95 \% \mathrm{Cl}$ : 0.84 0.91), twin births $(\mathrm{AOR}=2.89,95 \% \mathrm{Cl}: 2.673 .14)$, and lack of women involvement in healthcare decision-making process ( $\mathrm{AOR}=1.10$, 95\%Cl: 1.06 1.13) were determinants of adverse birth outcomes.

Conclusion: This study showed that the magnitude of adverse birth outcomes was high, abnormal baby size and preterm births were the most common adverse birth outcomes. This finding suggests that encouraging antenatal care follow-ups and socio-economic conditions of women are essential. Moreover, special attention should be given to multiple pregnancies, improving healthcare accessibilities to rural areas, and women's involvement in healthcare decision-making.
\end{abstract}

Keywords: Adverse birth outcomes, Determinants, Sub-Saharan Africa

\footnotetext{
*Correspondence: kokusisay23@gmail.com

Department of Epidemiology and Biostatistics, College of Medicine and Health Sciences, Institute of Public Health, University of Gondar, Gondar, Ethiopia
}

(c) The Author(s). 2021 Open Access This article is licensed under a Creative Commons Attribution 4.0 International License, which permits use, sharing, adaptation, distribution and reproduction in any medium or format, as long as you give appropriate credit to the original author(s) and the source, provide a link to the Creative Commons licence, and indicate if changes were made. The images or other third party material in this article are included in the article's Creative Commons licence, unless indicated otherwise in a credit line to the material. If material is not included in the article's Creative Commons licence and your intended use is not permitted by statutory regulation or exceeds the permitted use, you will need to obtain permission directly from the copyright holder. To view a copy of this licence, visit http://creativecommons.org/licenses/by/4.0/. The Creative Commons Public Domain Dedication waiver (http://creativecommons.org/publicdomain/zero/1.0/) applies to the data made available in this article, unless otherwise stated in a credit line to the data. 


\section{Background}

According to the global report, about 2.9 million babies die in the first month of life, of which preterm births, complications during pregnancy, and sepsis are the leading causes of death [1-3]. Particularly, adverse birth outcomes contributed to more than $75 \%$ of neonatal deaths occurred in the first weeks of life [1]. Adverse birth outcomes are defined by the World Health Organization as events of low birth weight, preterm birth, stillbirth, or perinatal deaths [4-7]. In particular, low birth weight (LBW) is often defined as a birth weight of below 2500 $\mathrm{g}$, which might be resulted from intrauterine growth retardations or shorter gestational age. Globally, about 15 to $20 \%$ of births weighted below $2500 \mathrm{~g}$ and associated with various neonatal health complications like hypothermia, hypoglycemia, and early deaths. Moreover, neurocognitive problems and developmental delays are the long-term complications of LBW that determine child survival and future health [4-12].

On top of that, about 15 million babies are born too preterm (often before 37 completed weeks of gestation) each year, of whom more than one million died immediately after birth due to complications and lack of appropriate treatment [13]. Many of the survivors face a lifetime of disability, including learning disabilities and visual and hearing problems [12]. Meanwhile, experiencing a stillbirth during pregnancy or childbirth is a tragedy insufficiently addressed in global agendas, policies, and funded programs.

Approximately, 2.6 million stillbirths occurred each year, of which about $50 \%$ of the incidents occurred just after the onset of labor [7]. About $84 \%$ of all stillbirths occur in low-and-middle-income countries including SSA where maternal health service coverage is low. Furthermore, stillbirth has psychological costs to women and their families, such as maternal depression, financial and economic repercussions, as well as stigma and taboo.

A variety of intertwined maternal, nutritional, environmental, and healthcare system factors contributed to the occurrence of adverse birth outcomes. Thus, advanced maternal age, level of education, antenatal care, home delivery, and healthcare access problems, and economic conditions, maternal clinical conditions like anemia, malaria, chronic illnesses, and HIV were determinants of adverse birth outcomes (Fig. 1) [13-20].

The government and stakeholders made tremendous efforts to curb the magnitude and impacts of adverse birth outcomes. Furthermore, the reduction of adverse birth outcomes like LBW, stillbirth, and preterm births are the parts of the Sustainable Development Goal (SDG) targeted under goals 3.1 and 3.2 [21]. Focused antenatal care, institutional delivery, nutritional counseling, and improving healthcare services availability and accessibility were some of the interventions used to reduce unfavorable birth outcomes in low-income settings. For instance, continuity of maternal healthcare services led by midwifery contributed to the reduction of preterm births by $24 \%$ witnessed by previous study results [22].

Most of the studies conducted previously had been single-centered and facility-based which was less likely to be representative. In addition, there is a need for quality, large, and population based-studies from SSA countries where a large share of adverse birth outcomes

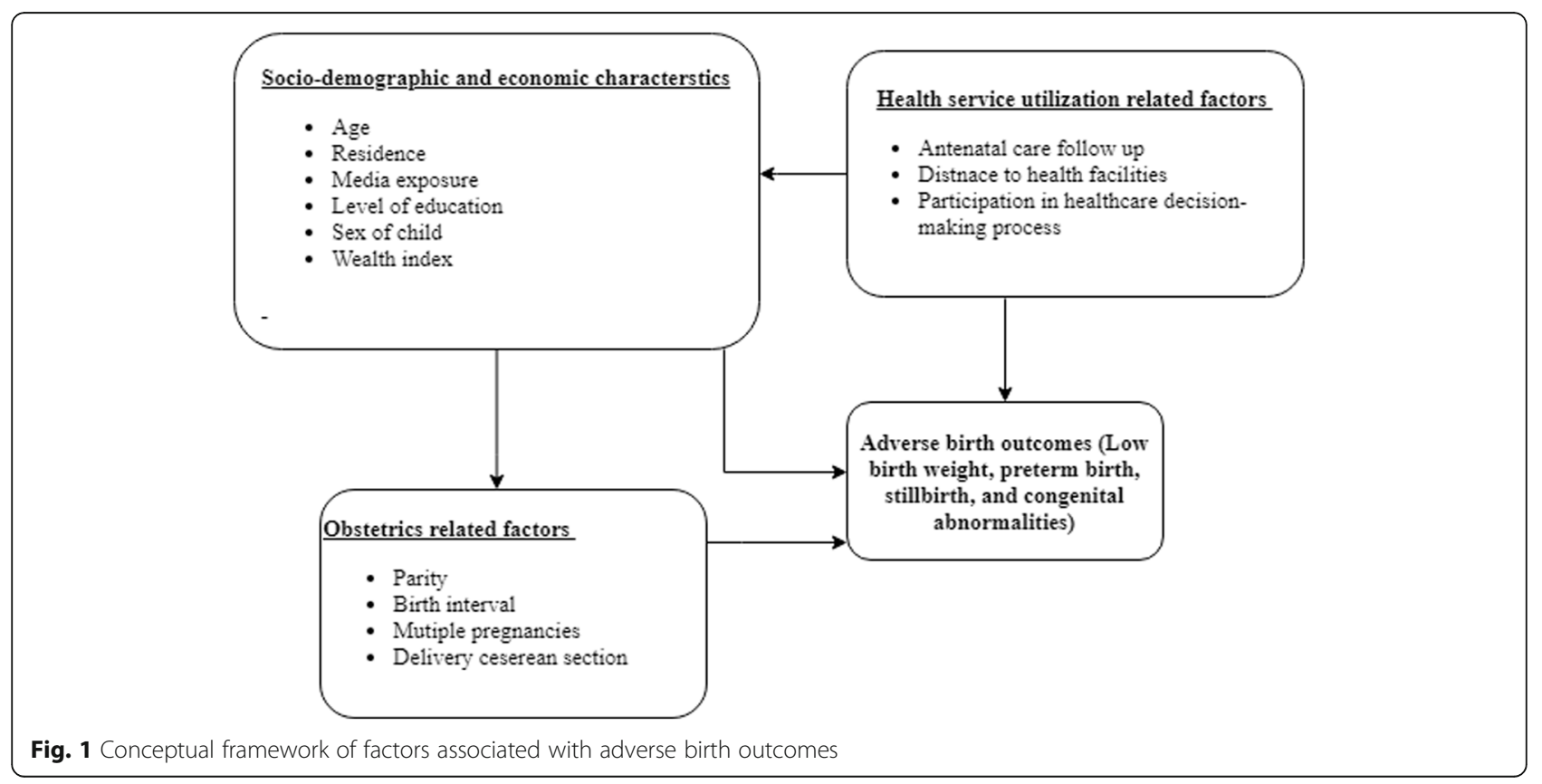


occurred. Hence, this study aimed to assess the pooled prevalence and determinants of adverse birth outcomes in SSA. A better understanding of the adverse birth outcomes could provide more generalizable evidence to justify the better quality of maternal healthcare and improving accessibility of health services in low-income countries. Moreover, evidence from this study could be helpful to design and integrated efforts at the regional level to hasten favorable birth outcomes.

\section{Method}

The most recent Demographic and Health Surveys (DHS) of ten Sub-African (SSA) countries (Angola, Congo, Cote d'Ivoire, Gambia, Lesotho, Liberia, Madagascar, Nigeria, Rwanda, Togo) data were used to make analysis of this study. The DHS is a part of the measure DHS programs that collect national information on basic health measures such as mortality, morbidity, and maternal and child health service utilization. Using the Kids Record (KR file) dataset, all births in the preceding five years before the survey were the study population. In the selected enumeration areas (EAs) births that had data about birth weight, gestational age at birth, and perinatal death records were included in the study. During the measure DHS survey, a multi-stage (twostage) stratified sampling technique was used to select study participants; children were nested within the enumeration areas. After the dataset was appended, the weighted sample size became 76,853 children and women who had given birth five years preceding the survey. The methodology section of the DHS report goes into great detail about the study participant selection and data collection [23].

\section{Measurements}

The main outcome variable of this study was adverse birth outcomes, which is defined as the presence of at least one or more of the following conditions in recent pregnancy (low birth weight, macrosomia, preterm birth, or stillbirth) $[13,19]$. The outcome variable was generated by composite low birth weight, macrosomia, stillbirth, and gestational age less than 37 weeks of pregnancy. Finally, the variable takes 1 if at least one of adverse birth outcomes reported which was labeled as "adverse birth outcome", and 0 otherwise.

\section{Independent variables}

Socio-demographic characteristics (residence, maternal education, husband education, maternal age, mother marital status, sex of the child, media exposure, household wealth index, and maternal working status), health service utilization and accessibility (women healthcare decision-making autonomy, ANC follow up, and distance to health facility), and obstetrics related characteristics (preceding birth interval, parity, type of birth, and delivery by CS) were explanatory variables identified after thorough review of literatures [13, 24-31] .

Short birth interval is defined as the time between two births which is less than 24 months [32]. Also, women's healthcare decision-making autonomy is the ability of the women to make decisions to use health care services and treatment options [25]. Finally, media exposure was defined as when a woman reads a newspaper or listens to the radio, or watches television at least three times per week.

\section{Data management and analysis}

Before any statistical analysis, the data were weighted using sampling weight based on primary sampling unit, and strata to restore the representativeness of the survey and take sampling design when calculating standard errors and reliable estimates. Cross-tabulations and summary statistics were done using STATA software version 14 (StataCorp.2015. Stata Statistical Software: Release 14. College Station, TX: StataCorp LP). The pooled prevalence of adverse birth outcomes with a 95\% Confidence Interval (CI) was reported using a forest plot. The DHS dataset has a hierarchical structure that failed to meet the standard logistic regression model assumptions of independent observation and equal variance. Meanwhile, the children were nested within a cluster household, and children from the same cluster were more similar than from other clusters. Therefore, a mixed effect logistic regression model (both fixed and random effect) was fitted to account for cluster variability by using the advanced models. The outcome variable of the study was binary, a standard logistic regression and Generalized Linear Mixed Models (GLMM) were fitted step by step. Because the models were nested, model fitness was compared using the Intra-class Correlation Coefficient (ICC), Likelihood Ratio (LR), Median Odds Ratio (MOR), and deviance (-2LLR) values. As a result, the mixed-effect logistic regression model with the lowest deviance value was selected as the most parsimonious model. (Shown on Supplementary file Table 1). In the bivariable analysis, variables with less than $0.2 p$-values were selected and entered into the multivariable mixed-effect logistic regression model. Adjusted Odds Ratios (AOR) with a 95\% CI were calculated in the multivariable model to see the strength of association between independent variables and adverse birth outcomes. Variables with a 0.05 p-value in the final model being used as a statistically significant determinant of adverse birth outcomes.

\section{Ethical consideration}

Permission for data access was obtained from measure demographic and health survey through an online request from http://www.dhsprogram.com. The data used 
Table 1 The socio-demographic and economic characteristics of the study population in Sub-Saharan Africa

\begin{tabular}{|c|c|c|}
\hline Variables & $\begin{array}{l}\text { Weighted } \\
\text { frequency }\end{array}$ & $\begin{array}{l}\text { Percentage } \\
\text { (\%) }\end{array}$ \\
\hline \multicolumn{3}{|l|}{ Country } \\
\hline Angola & 7154 & 9.3 \\
\hline Congo & 10,663 & 13.9 \\
\hline Côte d'Ivoire & 2105 & 2.7 \\
\hline Gambia & 14,605 & 19 \\
\hline Lesetho & 10,415 & 13.6 \\
\hline Liberia & 7783 & 10.1 \\
\hline Madagascar & 5201 & 6.8 \\
\hline Nigeria & 3081 & 4 \\
\hline Rwanda & 8156 & 10.6 \\
\hline Togo & 7690 & 10 \\
\hline \multicolumn{3}{|l|}{ Residence } \\
\hline Urban & 28,825 & 37.5 \\
\hline Rural & 48,028 & 62.5 \\
\hline \multicolumn{3}{|l|}{ Maternal age } \\
\hline $15-19$ & 4385 & 5.7 \\
\hline $20-29$ & 39,255 & 51.1 \\
\hline $30-39$ & 27,325 & 35.5 \\
\hline $40-49$ & 5878 & 7.7 \\
\hline \multicolumn{3}{|l|}{ Mothers education status } \\
\hline No & 15,158 & 19.7 \\
\hline Primary & 31,832 & 41.4 \\
\hline Secondary and above & 29,863 & 38.9 \\
\hline \multicolumn{3}{|l|}{ Husband education status } \\
\hline No & 9921 & 12.9 \\
\hline Primary & 22,977 & 29.9 \\
\hline Secondary and above & 43,955 & 57.2 \\
\hline \multicolumn{3}{|l|}{ Marital status } \\
\hline Married & 64,416 & 83.8 \\
\hline $\begin{array}{l}\text { Divorced/widowed/not living } \\
\text { together }\end{array}$ & 12,437 & 16.2 \\
\hline \multicolumn{3}{|l|}{ Wealth status } \\
\hline Poor & 27,538 & 35.8 \\
\hline Middle & 15,470 & 20.1 \\
\hline Rich & 33,845 & 44.1 \\
\hline \multicolumn{3}{|l|}{ Woman in paid employment } \\
\hline No & 24,789 & 32.3 \\
\hline Yes & 52,064 & 67.7 \\
\hline \multicolumn{3}{|c|}{ Women involvement in healthcare decision-making } \\
\hline No & 45,304 & 58.9 \\
\hline Yes & 31,549 & 41.1 \\
\hline \multicolumn{3}{|l|}{ Media exposure } \\
\hline No & 51,947 & 67.6 \\
\hline
\end{tabular}

Table 1 The socio-demographic and economic characteristics of the study population in Sub-Saharan Africa (Continued)

\begin{tabular}{lll}
\hline Variables & $\begin{array}{l}\text { Weighted } \\
\text { frequency }\end{array}$ & $\begin{array}{l}\text { Percentage } \\
\text { (\%) }\end{array}$ \\
\hline Yes & 24,906 & 32.4 \\
Experienced intimate partner beating & \\
Yes & 26,391 & 34.3 \\
No & 50,462 & 65.7 \\
\hline
\end{tabular}

for this study were publicly available with no personal identifier.

\section{Result}

\section{Socio-demographic characteristics}

The median age of the women in this sample was 28 years, with an interquartile range of 24 to 28 years, and half of them (51.1\%) were between the ages of 20 and 29 years. Nearly two-thirds of mothers (62.5\%) lived in rural areas, $19.7 \%$ had no formal schooling, and $83.8 \%$ were married at the time of data collection. Whilst more than one-third (34.3\%) of women experienced physical violence (beating) from the intimate partner due to the reason of refusals for sex, neglect of a child, and goes out of home without telling to the husband (Table 1).

\section{Obstetrics characteristics of women in SSA}

About $71.4 \%$ of women had antenatal care follow up for the recent pregnancies, $94.2 \%$ of women gave birth in health institutions, of whom $7.6 \%$ births were by cesarean section mode of delivery. The majority (87.7\%) women had greater than 24 birth months' of the interval from the preceding births and $15.2 \%$ were on the birth order of 6th and above (Table 2).

\section{The pooled prevalence of the adverse birth outcome in} SSA

The prevalence of adverse birth outcomes in SubSaharan countries was $29.7 \%$ with a $95 \%$ CI of 29.4 to $30.03 \%$, variations among countries also observed ranged from $17.4 \%$ in Madagascar to $42.6 \%$ in Lesotho (Fig. 2). More specifically, the rate of stillbirth was 11.5 per 1000 births; with preterm birth, fetal low birth weight, and macrosomia accounted for 7.6, 14.7, and $25.1 \%$ of all births, respectively. Of the reported adverse birth outcomes; macrosomia, low birth weight, preterm birth, and stillbirth accounted for $44,31 \%, 22$, and $3 \%$ of cases, respectively, and $3.24 \%$ had more than one adverse birth outcome.

\section{Determinants of adverse birth outcomes in SSA}

In the multivariable mixed-effect logistic regression analysis, sex of a child, maternal level of education, socioeconomic status, intimate partner violence (beating), 
Table 2 Maternal obstetrics characteristics of the study population in Sub-Saharan Africa

\begin{tabular}{|c|c|c|}
\hline Characteristics & Frequency & Percentage \\
\hline \multicolumn{3}{|c|}{ Number of ANC visits } \\
\hline No visit & 21,948 & 28.6 \\
\hline $1-3$ visits & 18,134 & 23.6 \\
\hline $4+$ visits & 36,771 & 47.8 \\
\hline \multicolumn{3}{|l|}{ Place of delivery } \\
\hline Home & 4467 & 5.8 \\
\hline Health institution & 72,386 & 94.2 \\
\hline \multicolumn{3}{|l|}{ Mode of delivery } \\
\hline Vaginal & 70,770 & 92.4 \\
\hline Cesarean section & 5797 & 7.6 \\
\hline \multicolumn{3}{|c|}{ Iron supplementation } \\
\hline Yes & 48,165 & 85.3 \\
\hline No & 8309 & 14.7 \\
\hline \multicolumn{3}{|l|}{ Sex of child } \\
\hline Male & 38,964 & 50.7 \\
\hline Female & 37,889 & 49.3 \\
\hline \multicolumn{3}{|l|}{ Type of pregnancy } \\
\hline Single & 74,179 & 96.5 \\
\hline Twin & 2674 & 3.5 \\
\hline \multicolumn{3}{|l|}{ Birth order } \\
\hline $1-2$ & 35,618 & 46.4 \\
\hline $3-5$ & 29,518 & 38.4 \\
\hline$\geq 6$ & 11,717 & 15.2 \\
\hline \multicolumn{3}{|c|}{ Preceding birth intervals } \\
\hline$<24$ & 9411 & 12.3 \\
\hline$\geq 24$ & 67,442 & 87.7 \\
\hline \multicolumn{3}{|c|}{ Ever termination of pregnancy } \\
\hline Yes & 9813 & 12.8 \\
\hline No & 67,040 & 87.2 \\
\hline
\end{tabular}

women-autonomy, distance to the health facility, parity, and twin birth were associated with adverse birth outcomes. Thus, the odds of adverse birth outcomes decreased among middle (AOR $=0.94,95 \% \mathrm{CI}: 0.900 .98$ ) and rich socioeconomic status $(\mathrm{AOR}=0.90,95 \% \mathrm{CI}: 0.90$ 0.99) compared to poorer women. Similarly, for women who attended secondary and above levels of education, the odds of adverse birth outcomes decreased by $13 \%$ $(\mathrm{AOR}=0.87,95 \% \mathrm{CI}: 0.820 .92)$ than those who had no formal education. Likewise, antenatal care visits and multiparity birth associated with $14 \% \quad(\mathrm{AOR}=0.86$, 95\%CI: 0.830 .89 ) and $12 \%$ (AOR $=0.88,95 \% \mathrm{CI}: 0.84$ 0.91) lower odds of adverse birth outcomes compared to those who had no follow-ups and those primiparous women, respectively. In addition, female child associated with $6 \%(\mathrm{AOR}=0.94,95 \% \mathrm{CI}: 0.910 .97)$ lower odds of adverse birth outcomes than males. Whilst, mothers who experienced intimate partner violence (beating) had $1.18(\mathrm{AOR}=1.18,95 \% \mathrm{CI}: 1.141 .22)$ times higher odds of adverse birth outcomes than women with no such history. In the same way, for women who didn't participate in healthcare decision-making, the odds of adverse birth outcomes were $1.10 \quad(\mathrm{AOR}=1.10,95 \% \mathrm{CI}$ : 1.06 1.13) times higher than participated in decision-making. Similarly, women who perceived distance to health facilities as big problems had 1.08 (AOR $=1.08,95 \% \mathrm{CI}$ : 1.04 1.11) times higher compared to the counterpart. Furthermore, twin birth was associated with 2.89 (AOR = 2.89, 95\%CI: 2.673 .14 ) times more likely to had adverse birth outcomes than singleton birth (Table 3).

\section{Discussion}

According to this report, the pooled prevalence of adverse birth outcomes was $29.7 \%$, with (95\% CI: 29.4 to 30.03\%). Stillbirth rate was 11.5 per 1000 births, with preterm birth, fetal low birth weight, and macrosomia accounted for 7.6, 14.7, and $25.1 \%$ of all births, respectively. A woman's level of education, socioeconomic status, intimate partner physical violence (beating), sex of child, women autonomy for health care decisionmaking, distance travel, twin birth, multiparity, and ANC follow-up were determinants of adverse birth outcomes. The rate of stillbirth in this study was lower than the results of 48.5 per 1000 births in Southeast Asia [33]. This could be because most of the stillbirths in the community are under-reported and is a common problem in SSA [34]. However, the magnitude of adverse birth outcomes in this study was higher than the study finding $18.3 \%$ in Ethiopia [19]. However, this study finding of low birth weight (14.7\%\%) and prematurity (7.6\%) were lower than the findings of LBW (19.6\%) and prematurity (17.7\%) among HIV-infected women in Uganda [20]. This could be because of chronic diseases and HIV/AIDS, in which highly active antiretroviral therapy (HAART) is associated with small gestational age and preterm labor among pregnant women [35]. Similarly, this study finding of low birth weight $(7.99 \%)$ and prematurity $(7.60 \%)$ was lower than the previous study finds of 12.36 and $8.28 \%$ among teenagers in the US [36]. This could be due to study population differences in teen ages associated with a higher risk of adverse birth outcomes.

Various maternal and contextual factors are associated with adverse birth outcomes, thus distance travel to health facilities associated with higher odds of adverse birth outcomes. This finding was consistent with those of studies in Africa [19, 24, 32, 37, 38]. This could be due to the fact long-distance travel restricts the utilization of basic maternal health services like ANC checkups and institutional delivery. Meanwhile, longdistance travel to health facilities also directly 
Proportions of adverse birth outcomes in SSA countries

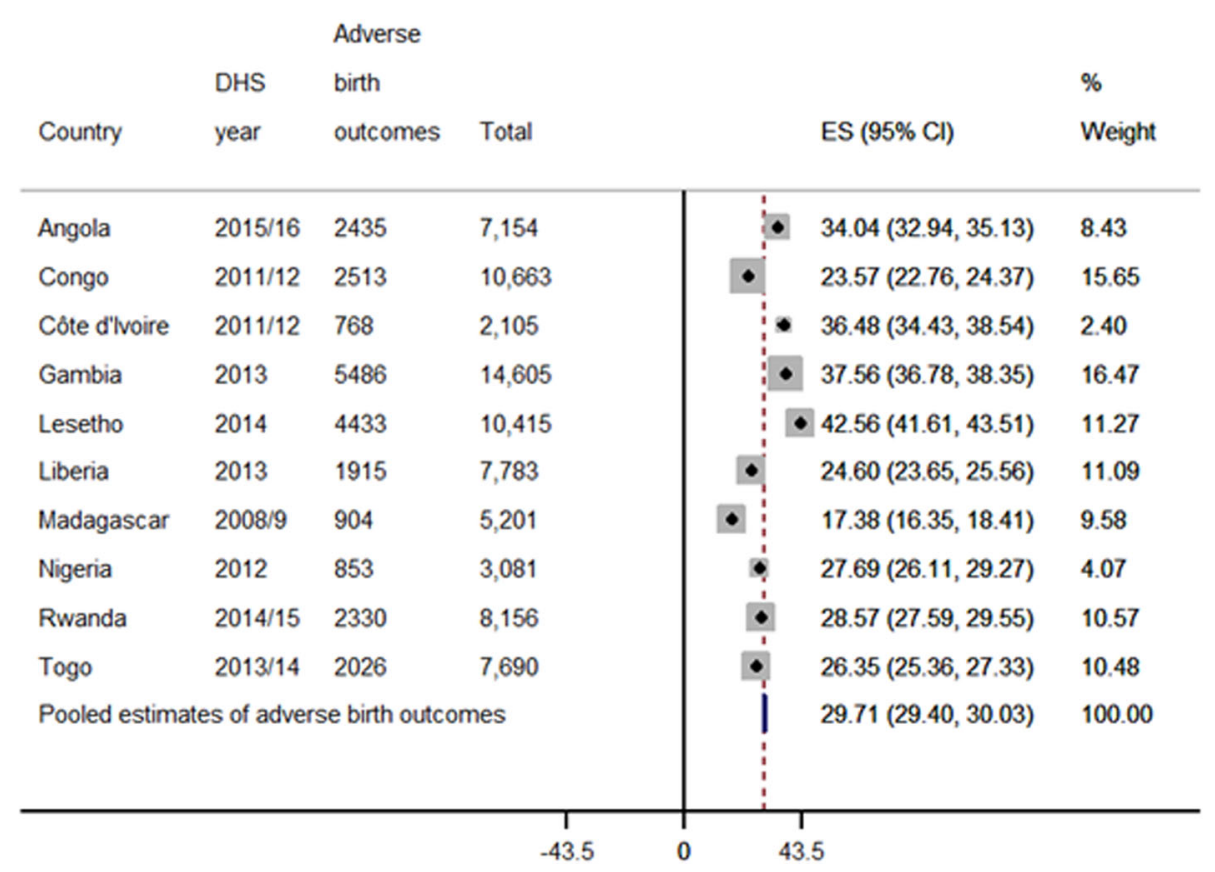

Fig. 2 Forest plot of adverse birth outcomes in Sub-Saharan Africa countries

responsible for perinatal deaths from fetal distresses [39]. Some countries like Ethiopia established maternal waiting areas (MWA) for mothers who came from hardto-reach areas [40]. Moreover, integrating emergency obstetrics transportation with complementary maternal health services avert adverse pregnancy outcomes and improves access to skilled obstetric services for women in LMICs [41]. Likewise, women experienced intimate partner physical violence (beating) associated with increased occurrence of adverse birth outcomes. This finding was consistent with previous study findings [42].

In contrast, birth interval above 24 months is associated with a decreased risk of adverse birth outcomes. This finding was consistent with those of studies SSA $[15,35,43-45]$. This could be due to the fact associated with gestational diabetes mellitus, and a narrow interpregnancy interval related to lower weight losses. In addition, female child associated with lower odds of adverse birth outcomes than males. This could be due to the differential effects of stress on female and male pregnancies which are supported by previous evidence [46].

This study also revealed that twin pregnancies were associated with increased risks of adverse birth outcomes. This finding was in agreement with previous studies [31, 47]. This could be due to the reason for the high rate of pre-eclampsia and antepartum hemorrhages during pregnancies that lead to unfavorable birth outcomes. Thus, a twin pregnancy is defined as a high-risk pregnancy with special attention, and birth preparedness and complication readiness counseling should be given to pregnant mothers. Furthermore, the study's findings point to the value of affordable imaging technology in low-income countries.

Likewise, women who didn't participate in healthcare decision-making were more likely to had adverse birth outcomes than participated in decision makings [27]. This might be due to the reason that women declined and less involvement in healthcare decision-making was associated with decreased utilization of antennal care and institutional delivery. Moreover, a woman decreased involvement in decision-making may indicate that she is exposed to intimate partner violence [27].

On the other hand, women who had antenatal care visits for the recent birth were associated with lower odds of adverse birth outcomes than those who had no follow-up visits. This finding was consistent with those of studies in SSA [18, 19, 27, 32, 37, 45]. Antenatal care checkups help to identify most at-risk pregnancies like intrauterine growth retardation, nutritional counseling, and supplementation of nutrient fortified foods. In addition, antenatal care visits allowed identifying diseases like HIV/AIDS, syphilis, malaria, and intestinal helminthiasis infection that could affect fetal outcomes. Therefore, further improvement of quality of antenatal care and mobilization of pregnant women to WHO recommended focused care would halt adverse birth 
Table 3 Multivariable multilevel logistic regression analysis to identify factors associated with low adverse birth outcomes in subSaharan Africa

\begin{tabular}{|c|c|c|c|c|}
\hline \multirow[t]{2}{*}{ Characteristics } & \multicolumn{2}{|c|}{ Adverse birth outcome } & \multicolumn{2}{|c|}{ Odds Ratio (OR) } \\
\hline & Yes & No & Crude OR & Adjusted OR \\
\hline \multicolumn{5}{|l|}{ Maternal age } \\
\hline $15-19$ & 1478 & 2917 & 1 & 1 \\
\hline $20-29$ & 12,181 & 27,074 & $0.91(0.850 .98)$ & $0.95(0.89$ 1.02) \\
\hline $30-39$ & 8217 & 19,108 & $0.91(0.850 .98)$ & $0.98(0.911 .07)$ \\
\hline $40-49$ & 1787 & 4091 & $0.86(0.861 .02)$ & 0.99 (0.89 1.09) \\
\hline \multicolumn{5}{|l|}{ Sex of child } \\
\hline Male & 12,215 & 26,749 & 1 & 1 \\
\hline Female & 11,448 & 26,441 & $0.94(0.910 .97)$ & $0.94(0.910 .97)^{*}$ \\
\hline \multicolumn{5}{|l|}{ Residence } \\
\hline Urban & 8204 & 20,621 & 1 & 1 \\
\hline Rural & 15,459 & 32,569 & $1.15(1.111 .19)$ & $1.02(0.981 .06)$ \\
\hline \multicolumn{5}{|c|}{ Maternal level of education } \\
\hline No formal education & 4669 & 10,489 & 1 & 1 \\
\hline Primary education & 10,956 & 20,876 & $1.00(0.961 .05)$ & $1.04(0.991 .09)$ \\
\hline Secondary and above & 8038 & 21,825 & $0.80(0.760 .84)$ & $0.87(0.820 .92)^{*}$ \\
\hline \multicolumn{5}{|l|}{ Media exposure } \\
\hline Yes & 7949 & 16,957 & $0.89(0.860 .92)$ & $0.97(0.941 .01)$ \\
\hline No & 15,714 & 36,233 & 1 & 1 \\
\hline \multicolumn{5}{|l|}{ Wealth index } \\
\hline Poor & 9190 & 18,348 & 1 & 1 \\
\hline Middle & 4790 & 10,680 & $0.90(0.860 .94)$ & $0.94(0.900 .98)^{*}$ \\
\hline Rich & 9683 & 24,162 & $0.82(0.800 .85)$ & $0.92(0.900 .99)^{*}$ \\
\hline \multicolumn{5}{|c|}{ Women didn't participate in healthcare decision making } \\
\hline Yes & 13,396 & 31,908 & 1 & 1 \\
\hline No & 10,267 & 21,282 & $1.12(1.091 .16)$ & $1.10(1.061 .13)^{*}$ \\
\hline \multicolumn{5}{|c|}{ Distance to a health facility } \\
\hline Big problems & 9215 & 17,979 & $1.13(1.091 .17)$ & $1.08(1.041 .11)^{*}$ \\
\hline No big problem & 14,448 & 35,211 & 1 & 1 \\
\hline \multicolumn{5}{|l|}{ ANC follow up } \\
\hline Yes & 7488 & 14,460 & $0.80(0.770 .82)$ & $0.86(0.830 .89)^{*}$ \\
\hline No & 16,175 & 38,730 & 1 & 1 \\
\hline \multicolumn{5}{|l|}{ Parity } \\
\hline $1-2$ births & 11,030 & 24,588 & 1 & 1 \\
\hline $3-5$ births & 8737 & 20,781 & $093(0.900 .96$ & $0.88(0.840 .91)^{*}$ \\
\hline$>=6$ births & 3896 & 7821 & $1.07(1.021 .12)$ & $0.97(0.881 .006)$ \\
\hline \multicolumn{5}{|l|}{ Birth interval } \\
\hline$<24$ months & 3014 & 6397 & 1 & 1 \\
\hline 24 and above months & 20,649 & 46,973 & $0.96(0.911 .00)$ & $0.95(0.901 .00)$ \\
\hline \multicolumn{5}{|c|}{ Experienced intimate partner beating } \\
\hline Yes & 8617 & 17,774 & $1.23(1.191 .27)$ & $1.18(1.141 .22)^{*}$ \\
\hline No & 15,046 & 35,416 & 1 & 1 \\
\hline
\end{tabular}

Type of birth 
Table 3 Multivariable multilevel logistic regression analysis to identify factors associated with low adverse birth outcomes in subSaharan Africa (Continued)

\begin{tabular}{|c|c|c|c|c|}
\hline \multirow[t]{2}{*}{ Characteristics } & \multicolumn{2}{|c|}{ Adverse birth outcome } & \multicolumn{2}{|c|}{ Odds Ratio (OR) } \\
\hline & Yes & No & Crude OR & Adjusted OR \\
\hline Single & 22,198 & 51,981 & 1 & \\
\hline Twin & 1465 & 1209 & 2.95 (2.95 3.19) & $2.89(2.673 .14)^{*}$ \\
\hline
\end{tabular}

* Shows a statistical significance of at $0.05 p$-value

outcomes and achievement of Sustainable development goals.

Similarly, better socio-economic attributes like a better level of education and wealthy economic conditions associated with a lower risk of adverse birth outcomes. This finding was consist of previous results $[15,35,48]$. Better socio-economic attributes might hasten healthseeking behaviors and maternal nutrition. In addition, it might be associated with good knowledge of danger signs of pregnancies and early initiation of antenatal follow-ups.

This research has implications for mothers, healthcare planners, and maternal health program coordinators who are working to develop evidence-based approaches to help achieve the Sustainable Development Goals (SDG). Furthermore, increasing healthcare access to rural and hard-to-reach areas and encouraging women's involvement in healthcare decision-making could help to minimize the extent of adverse birth outcomes. Furthermore, healthcare providers should pay more time and attention to women who had a history of partner physical violence, multiple pregnancies and have difficult labors.

This study has the strengths of a large sample size from multiple countries that would help to assess the regional situation of adverse birth outcomes. In addition, factors identified from these pooled studies might be used areas interventions for stakeholders. However, due to reasons of secondary data sources, some important clinical parameters like gestational diabetes and chronic disease conditions were not assessed. In addition, this study included only a few countries from the SubSaharan region that leads to under representations. Moreover, adverse birth outcomes reported in this study were based on the recent pregnancies from the Demography and health surveys.

\section{Conclusion}

This study showed that the magnitude of adverse birth outcomes was high, abnormal baby size and preterm births were the most common types. Problems of adverse birth outcomes were more common among women who experienced intimate partner physical violence (beating), distance travel, multiple pregnancies, and lack of involvement in the healthcare decisionmaking process. According to the findings, improving maternal health services such as antenatal care is critical in reducing adverse birth outcomes. Furthermore, this research emphasizes the importance of paying particular attention to women who have had multiple births, expanding healthcare coverage to rural areas, and promoting women's participation in the healthcare decision-making process.

\section{Abbreviations \\ ABO: Adverse Birth Outcomes; ANC: Antenatal Care; AOR: Adjusted Odds Ratio; Cl: Confidence Interval; DHS: Demographic and Health Survey; EA: Enumeration Area; LBW: Low Birth Weight; LLR: Likelihood Ratio; SD: Standard Deviation; SGD: Sustainable Development Goal; SSA: Sub- Saharan Africa; USA: United States of America}

\section{Supplementary Information}

The online version contains supplementary material available at https://doi. org/10.1186/s12889-021-11113-z.

Additional file 1: Supplementary file Table 1: Model comparison and random effect results.

\section{Acknowledgments}

We would like to thank the Ethiopian Central Statistics Agency for providing us with all the relevant secondary data used in this study. Finally, we would like to thank all who directly or indirectly supported us.

Authors' contributions

KST, MMS, GAT, and ZTT conceived the study, data analysis, drafted the manuscript, and critically reviewed the manuscript. Read and approved the final version of the manuscript.

\section{Funding}

We didn't receive external funds for this research.

\section{Availability of data and materials}

The datasets used in this analysis are publicly available data from the DHS program, which can be accessed after filling out a data request form at http://www.dhsprogram.com.

\section{Declarations}

Ethics approval and consent to participate

Ethical clearance was obtained from measure DHS through filling requesting a form for accessing data. The data used in this study are publicly available, aggregated secondary data that hasn't any personal identifying information that can be linked to study participants. The confidentiality of data was maintained anonymously.

Consent for publication

Not applicable as there are no image or other confidentiality-related issues.

Competing interests

The authors declared that they have no competing interests. 
Received: 16 December 2020 Accepted: 23 May 2021 Published online: 07 June 2021

\section{References}

1. Ballot DE, Chirwa T, Ramdin T, Chirwa L, Mare I, Davies VA, et al Comparison of morbidity and mortality of very low birth weight infants in a central Hospital in Johannesburg between 2006/2007 and 2013. BMC Pediatr. 2015;15(1):20. https://doi.org/10.1186/s12887-015-0337-4.

2. Blencowe $H$, Krasevec J, de Onis M, Black RE, An X, Stevens GA, et al. National, regional, and worldwide estimates of low birthweight in 2015, with trends from 2000: a systematic analysis. Lancet Glob Health. 2019;7(7): e849-60. https://doi.org/10.1016/S2214-109X(18)30565-5.

3. You D, et al. Levels and trends in child mortality. Report 2015. In: Estimates developed by the UN Inter-agency Group for Child Mortality Estimation; 2011.

4. Agbozo F, Abubakari A, der J, Jahn A. Prevalence of low birth weight, macrosomia and stillbirth and their relationship to associated maternal risk factors in Hohoe municipality, Ghana. Midwifery. 2016;40:200-6. https://doi. org/10.1016/j.midw.2016.06.016.

5. Amhara E. A review of low birth weight in Ethiopia: socio-demographic and obstetric risk factors. Global J Res Rev. 2018;5(1):4.

6. Bansal P, Garg S, Upadhyay HP. Prevalence of low birth weight babies and its association with socio-cultural and maternal risk factors among the institutional deliveries in Bharatpur, Nepal. Asian J Med Sci. 2019;10(1):77-85.

7. Blencowe $\mathrm{H}$. Counting the smallest: data to estimate global stillbirth, preterm birth and low birthweight rates (Doctoral dissertation, London School of Hygiene \& Tropical Medicine)

8. Class QA, Rickert ME, Lichtenstein P, D'Onofrio BM. Birth weight, physical morbidity, and mortality: a population-based sibling-comparison study. Am J Epidemiol. 2014;179(5):550-8. https://doi.org/10.1093/aje/kwt304.

9. Dahlui M, Azahar N, Oche OM, Aziz NA. Risk factors for low birth weight in Nigeria: evidence from the 2013 Nigeria demographic and health survey. Glob Health Action. 2016;9(1):28822. https://doi.org/10.3402/gha.v9.28822.

10. Hughes MM, Black RE, Katz J. 2500-g low birth weight cutoff: history and implications for future research and policy. Matern Child Health J. 2017 ; 21(2):283-9. https://doi.org/10.1007/s10995-016-2131-9.

11. Baran M, Celikkalkan K, Cagan Appak Y, Karakoyun M, Bozkurt M, Kocyigit C, et al. Body fat mass is better indicator than indirect measurement methods in obese children for fatty liver and metabolic syndrome. Sci Med J. 2019; 1(4):168-75. https://doi.org/10.28991/SciMedJ-2019-0104-2.

12. Swierczynski A. Pathogenicity of endocrine dysregulation in autism: the role of the melanin-concentrating hormone system. SciMed J. 2019;1(2):74-111. https://doi.org/10.28991/SciMedJ-2019-0102-5

13. Rahman MM, Abe SK, Rahman MS, Kanda M, Narita S, Bilano V, et al. Maternal anemia and risk of adverse birth and health outcomes in low-and middle-income countries: systematic review and meta-analysis, 2. Am J Clin Nutr. 2016;103(2):495-504. https://doi.org/10.3945/ajcn.115.107896.

14. Chibwesha CJ, Zanolini A, Smid M, Vwalika B, Phiri Kasaro M, Mwanahamuntu $M$, et al. Predictors and outcomes of low birth weight in Lusaka, Zambia. Int J Gynecol Obstet. 2016;134(3):309-14. https://doi.org/1 0.1016/j.ijgo.2016.03.021

15. Gebremeskel F, et al. Determinants of adverse birth outcome among mothers who gave birth at hospitals in Gamo Gofa Zone, southern Ethiopia: a facility based case control study. Qual Prim Care. 2017;25(5):259-66.

16. Kader M, Perera NKP. Socio-economic and nutritional determinants of low birth weight in India. N Am J Med Sci. 2014;6(7):302-8. https://doi.org/10.41 03/1947-2714.136902.

17. Kebede AS, Muche AA, Alene AG. Factors associated with adverse pregnancy outcome in Debre Tabor town, Northwest Ethiopia: a case control study. BMC Res Notes. 2018;11(1):820. https://doi.org/10.1186/s131 04-018-3932-2.

18. Siza J. Risk factors associated with low birth weight of neonates among pregnant women attending a referral hospital in northern Tanzania. Tanzania J Health Res. 2008;10(1):1-8. https://doi.org/10.4314/thrb.v1 $0 i 1.14334$

19. Tsegaye B, Kassa A. Prevalence of adverse birth outcome and associated factors among women who delivered in Hawassa town governmental health institutions, South Ethiopia, in 2017. Reprod Health. 2018;15(1):193. https://doi.org/10.1186/s12978-018-0631-3.

20. Young S, Murray K, Mwesigwa J, Natureeba P, Osterbauer B, Achan J, et al. Maternal nutritional status predicts adverse birth outcomes among HIV- infected rural Ugandan women receiving combination antiretroviral therapy. PLoS One. 2012;7(8):e41934. https://doi.org/10.1371/journal.pone. 0041934.

21. Bahl $R$, et al. Setting research priorities to reduce global mortality from preterm birth and low birth weight by 2015. J Global Health. 2012;2(1).

22. Tolefac PN, et al. Ten years analysis of stillbirth in a tertiary hospital in subSahara Africa: a case control study. BMC Res Notes. 2017;10(1):1-6.

23. Selftreported VODO, Malawi HSI. DHS Methodological reports 10; 2014.

24. Adane AA, Ayele TA, Ararsa LG, Bitew BD, Zeleke BM. Adverse birth outcomes among deliveries at Gondar University hospital, Northwest Ethiopia. BMC Pregnancy Childbirth. 2014;14(1):90. https://doi.org/10.11 86/1471-2393-14-90.

25. Adokiya MN, Boah M, Adampah T. Women's autonomy and modern contraceptive use in Ghana: a secondary analysis of data from the 2014 Ghana Demographic and Health Survey. Eur J Contracept Reprod Health Care. 2021:1-7.

26. Althabe F, et al. Adverse maternal and perinatal outcomes in adolescent pregnancies: the global Network's maternal newborn health registry study. Reprod Health. 2015;12(2):1-9.

27. Hill A, Pallitto C, McCleary-Sills J, Garcia-Moreno C. A systematic review and meta-analysis of intimate partner violence during pregnancy and selected birth outcomes. Int J Gynecol Obstet. 2016;133(3):269-76. https://doi.org/1 0.1016/j.ijgo.2015.10.023

28. Kozuki N, Katz J, Khatry SK, Tielsch JM, LeClerq SC, Mullany LC. Risk and burden of adverse intrapartum-related outcomes associated with noncephalic and multiple birth in rural Nepal: a prospective cohort study. BMJ Open. 2017;7(4):e013099. https://doi.org/10.1136/bmjopen-2016-013099.

29. Said AS, Manji KP. Risk factors and outcomes of fetal macrosomia in a tertiary Centre in Tanzania: a case-control study. BMC Pregnancy Childbirth. 2016;16(1):1-8.

30. Zanardi DM, et al. Adverse perinatal outcomes are associated with severe maternal morbidity and mortality: evidence from a national multicentre cross-sectional study. Arch Gynecol Obstet. 2019;299(3):645-54. https://doi. org/10.1007/s00404-018-5004-1.

31. Zhu C, Wang M, Niu G, Yang J, Wang Z. Obstetric outcomes of twin pregnancies at advanced maternal age: a retrospective study. Taiwanese J Obstetrics Gynecol. 2018;57(1):64-7. https://doi.org/10.1016/j.tjog.2017.12.010.

32. Muchemi OM, Echoka E, Makokha A. Factors associated with low birth weight among neonates born at Olkalou District Hospital, Central Region, Kenya. Pan Afr Med J. 2015;20(1)

33. Ali SA, et al. Hemoglobin concentrations and adverse birth outcomes in south Asian pregnant women: findings from a prospective maternal and neonatal health registry. Reprod Health. 2020;17(2):1-13.

34. Kiguli J, Namusoko S, Kerber K, Peterson S, Waiswa P. Weeping in silence: community experiences of stillbirths in rural eastern Uganda. Glob Health Action. 2015;8(1):24011. https://doi.org/10.3402/gha.v8.24011.

35. Kebede B, Andargie G, Gebeyehu A. Birth outcome and correlates of low birth weight and preterm delivery among infants born to HIV-infected women in public hospitals of Northwest Ethiopia; 2013.

36. Chen X-K, Wen SW, Fleming N, Demissie K, Rhoads GG, Walker M. Teenage pregnancy and adverse birth outcomes: a large population based retrospective cohort study. Int J Epidemiol. 2007;36(2):368-73. https://doi. org/10.1093/ije/dyl284.

37. Niyitegeka J, Nshimirimana G, Silverstein A, Odhiambo J, Lin Y, Nkurunziza T, et al. Longer travel time to district hospital worsens neonatal outcomes: a retrospective cross-sectional study of the effect of delays in receiving emergency cesarean section in Rwanda. BMC Pregnancy Childbirth. 2017; 17(1):242. https://doi.org/10.1186/s12884-017-1426-1.

38. Sebayang SK, Dibley MJ, Kelly PJ, Shankar AV, Shankar AH, on behalf of the SUMMIT Study Group. Determinants of low birthweight, small-forgestational-age and preterm birth in Lombok, Indonesia: analyses of the birthweight cohort of the SUMMIT trial. Tropical Med Int Health. 2012;17(8): 938-50. https://doi.org/10.1111/j.1365-3156.2012.03039.x.

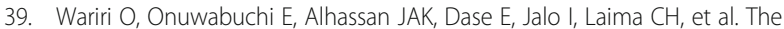
influence of travel time to health facilities on stillbirths: a geospatial casecontrol analysis of facility-based data in Gombe, Nigeria. Plos one. 2021; 16(1):e0245297. https://doi.org/10.1371/journal.pone.0245297.

40. Kelly J, Kohls E, Poovan P, Schiffer R, Redito A, Winter $\mathrm{H}$, et al. The role of a maternity waiting area (MWA) in reducing maternal mortality and stillbirths in high-risk women in rural Ethiopia. BJOG Int J Obstet Gynaecol. 2010; 117(11):1377-83. https://doi.org/10.1111/j.1471-0528.2010.02669.x. 
41. Alaofe $\mathrm{H}$, et al. Emergency Transportation Interventions for Reducing Adverse Pregnancy Outcomes in Low-and Middle-Income Countries: A Systematic Review. Ann Global Health. 2020;86(1).

42. Laelago T, Belachew T, Tamrat M. Effect of intimate partner violence on birth outcomes. Afr Health Sci. 2017;17(3):681-9. https://doi.org/10.4314/ahs. v17i3.10.

43. Regan AK, Gissler M, Magnus MC, Håberg SE, Ball S, Malacova E, et al. Association between interpregnancy interval and adverse birth outcomes in women with a previous stillbirth: an international cohort study. Lancet. 2019;393(10180):1527-35. https://doi.org/10.1016/S0140-6736(18)32266-9.

44. Laptook AR, O'Shea TM, Shankaran S, Bhaskar B, NICHD Neonatal Network. Adverse neurodevelopmental outcomes among extremely low birth weight infants with a normal head ultrasound: prevalence and antecedents. Pediatrics. 2005;115(3):673-80. https://doi.org/10.1542/peds.2004-0667.

45. Lema D. Determinants ofLlow Birth Weight in Debre Berehan Referal Hospital, North Shoa Zone, Amhara Regional State, Ethiopia (A Case-Control Study): AAU; 2015

46. Wainstock T, Shoham-Vardi I, Glasser S, Anteby E, Lerner-Geva L. Fetal sex modifies effects of prenatal stress exposure and adverse birth outcomes. Stress. 2015;18(1):49-56. https://doi.org/10.3109/10253890.2014.974153.

47. Francisco C, Wright D, Benkő Z, Syngelaki A, Nicolaides KH. Hidden high rate of pre-eclampsia in twin compared with singleton pregnancy. Ultrasound Obstet Gynecol. 2017;50(1):88-92. https://doi.org/10.1002/uog.1 7470 .

48. Gedefaw G, Alemnew B, Demis A. Adverse fetal outcomes and its associated factors in Ethiopia: a systematic review and meta-analysis. BMC Pediatr. 2020;20:1-12.

\section{Publisher's Note}

Springer Nature remains neutral with regard to jurisdictional claims in published maps and institutional affiliations.

Ready to submit your research? Choose BMC and benefit from:

- fast, convenient online submission

- thorough peer review by experienced researchers in your field

- rapid publication on acceptance

- support for research data, including large and complex data types

- gold Open Access which fosters wider collaboration and increased citations

- maximum visibility for your research: over $100 \mathrm{M}$ website views per year

At $\mathrm{BMC}$, research is always in progress.

Learn more biomedcentral.com/submissions 